Article

\title{
Temperature-Dependent Enhancement Effects for TBD (1,5,7-Triazabicyclo[4.4.0]dec-5-ene) with 2-Methylimidazole-Intercalated $\alpha$-Zirconium Phosphate as a Latent Thermal Initiator in the Reaction of Glycidyl Phenyl Ether
}

\author{
Osamu Shimomura *(D), Suguru Sasaki, Kaori Kume, Atsushi Ohtaka and Ryôki Nomura \\ Department of Applied Chemistry, Osaka Institute of Technology, 5-16-1 Omiya, Ashahi-ku, \\ Osaka 535-8585, Japan \\ * Correspondence: osamu.shimomura@oit.ac.jp; Tel.: +81-6-6954-4269
}

Received: 28 May 2019; Accepted: 27 June 2019; Published: 30 June 2019

\begin{abstract}
The catalytic effects of 1,1,3,3-Tetramethylguanidine (TMG), 1,5,7-Triazabicyclo[4.4.0]dec-5-ene (TBD), 7-Methyl-1,5,7-triazabicyclo[4.4.0]dec-5-ene (MTBD), 1,8-diazabicyclo[5.4.0]undec-7-ene (DBU), and 1,5-diazabicyclo[4.3.0]non-5-ene (DBN) in the reaction with glycidyl phenyl ether (GPE) at $40{ }^{\circ} \mathrm{C}$ were investigated. For the reaction, the \%conversion of GPE was only $11 \%$, carried out at $40{ }^{\circ} \mathrm{C}$ over 14 days in the presence of TBD.Additionally, there was little catalytic activity for the same reaction performed under typical storage conditions at $25^{\circ} \mathrm{C}$. The effect of TBD with 2-methylimidazole-intercalated $\alpha$-zirconium phosphate ( $\alpha$-ZrP.2MIm), as a latent thermal initiating system in the reaction with GPE, was then examined. The reaction did not proceed within $1 \mathrm{~h}$ at $80^{\circ} \mathrm{C}$. On increasing the temperature to $120^{\circ} \mathrm{C}$, the \%conversion reached $75 \%$ for reaction at $1 \mathrm{~h}$. Under typical storage conditions ( 7 days at $25^{\circ} \mathrm{C}$ ), the \%conversion of GPE was only $7 \%$. With addition of TBD to $\alpha$-ZrP.2MIm, reagent stability was maintained, and the polymerization reaction proceeded rapidly with the application of heat.
\end{abstract}

Keywords: $\alpha$-zirconium phosphate; intercalation; 2-methylimidazole; TBD; latent thermal initiator

\section{Introduction}

There has been considerable interest in the development of latent polymerization catalysts and initiators that are inert in monomer or prepolymer systems under typical storage conditions. Latent thermal initiators must remain inactive under storage conditions, but show high activity at specific temperatures [1-10]. Latent thermal initiators are used in adhesives, sealing agents, electrical devices, paints, and composite materials. One-pot resin composites using a latent thermal initiator offer some attractive features for synthesis: (1) weighing errors are eliminated and there is no requirement for mixing at time of use, (2) the reactions may be automated, and (3) it is possible to reduce resin waste because the resin may be stored for long periods. Thus, the development of latent thermal initiators with high storage stability and high reactivity at designated temperatures is very important for synthetic applications in the chemicals industry.

We have previously reported that primary alkylamines intercalated with $\alpha$-zirconium phosphate $(\alpha-\mathrm{ZrP})$ may serve as latent thermal initiators in the reaction of glycidyl phenyl ether (GPE) [11,12], and that the compounds 1,4-diazabicyclo[2,2,2]octane (DABCO), 1,8-diazabicyclo[5,4,0]undec-7-ene (DBU), imidazole (Im), 2-methylimidazole (2MIm), 2-ethyl-4-methylimidazole (2E4MIm), and benzimidazole (Bim) intercalated with $\alpha$-ZrP show good performance as latent thermal initiators in the reaction of GPE 
with hexahydro-4-methylphthalic anhydride (MHHPA) [13-16]. However, it is important to develop a highly active latent initiating system to avoid the need for high-temperature curing. Therefore, using GPE as a model epoxy compound, we have studied the enhancement effects of bases with $\alpha$-ZrP.2MIm as a potential thermal latent initiator in the acceleration of the reaction with GPE.

\section{Results and Discussion}

The use of latent thermal initiators enables stable storage conditions to be maintained for relatively long periods of time without the occurrence of undesirable curing reactions. To evaluate the effect on the storage stability of GPE, curing experiments in the presence of the following bases, 1,1,3,3-Tetramethylguanidine (TMG), 1,5,7-Triazabicyclo[4.4.0]dec-5-ene (TBD), 7-Methyl-1,5,7-triazabicyclo[4.4.0]dec-5-ene (MTBD), 1,8-diazabicyclo[5.4.0]undec-7-ene (DBU), and 1,5-diazabicyclo[4.3.0]non-5-ene (DBN) were carried out at a temperature of $40{ }^{\circ} \mathrm{C}$ (Figure 1a and Scheme 1). The \%conversion values for GPE with TMG, DBN, DBU, and MTBD using a 20\% conversion level as a typical benchmark were 22\% (1 day), 20\% (1 day), 26\% ( 2 days), and 32\% (4 days), respectively. Thus, the aforementioned bases in GPE did not show good storage stability at $40{ }^{\circ} \mathrm{C}$. Further, for the addition of TBD, the $\%$ conversion value for GPE at $40^{\circ} \mathrm{C}$ was only $11 \%$ after 14 days, that is, the addition of TBD hardly accelerated the reaction of GPE. The \%conversion values for GPE with TBD for a $1 \mathrm{~h}$ reaction over the temperature range 60 to $120^{\circ} \mathrm{C}$ are shown in Figure $1 \mathrm{~b}$, and it is clear that the polymerization reaction did not proceed under the specified conditions.
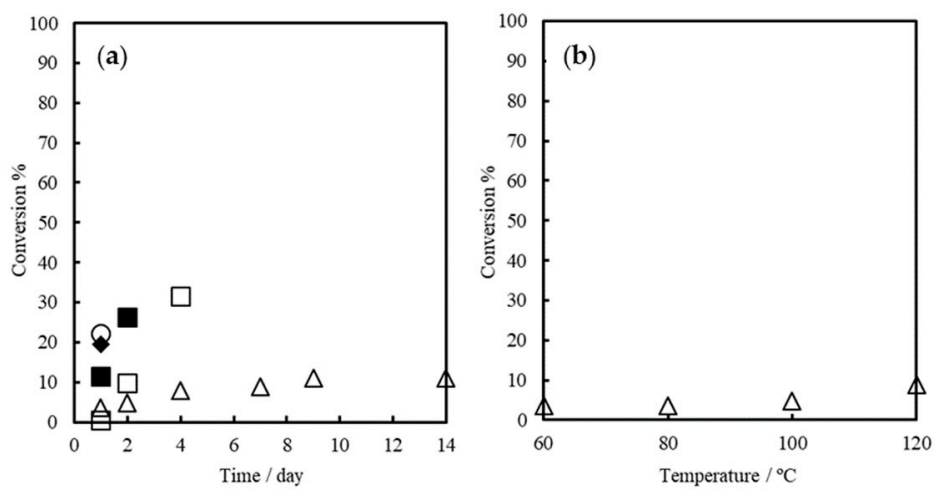

Figure 1. (a) The \%conversion values for glycidyl phenyl ether (GPE) as a function of time during reaction with 1,1,3,3-Tetramethylguanidine (TMG) ( $\bigcirc$ ), 1,5,7-Triazabicyclo[4.4.0]dec-5-ene (TBD) $(\Delta)$, MTBD (ם), 7-Methyl-1,5,7-triazabicyclo[4.4.0]dec-5-ene (DBU) (๘), and 1,5-diazabicyclo[4.3.0]non-5-ene $(\mathrm{DBN})(\diamond)$ at $40{ }^{\circ} \mathrm{C}$; (b) The \%conversion values for GPE as a function of temperature during reaction with $\operatorname{TBD}(\Delta)$.

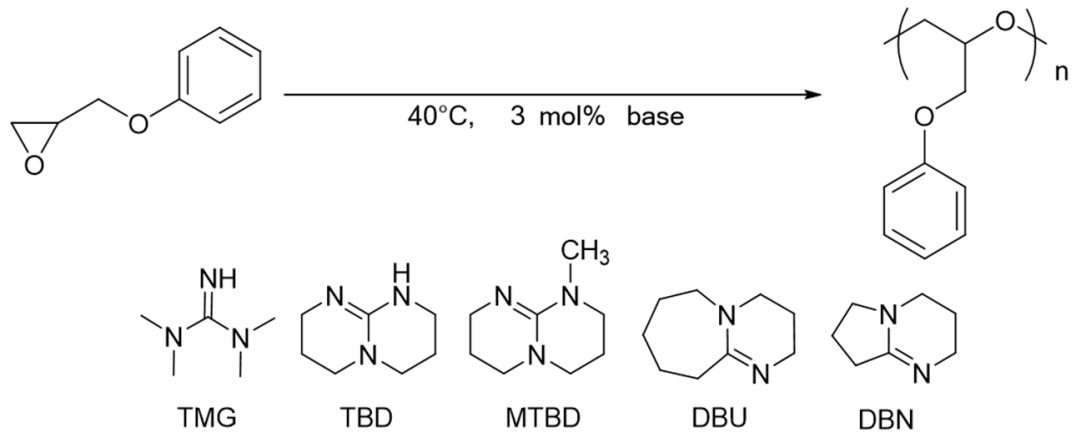

Scheme 1. Reaction of GPE with bases.

The \%conversions values for the reactions of GPE with TBD and $\alpha$-ZrP.2MIm (abbreviated as $\alpha$-ZrP.2MIm-T) over $1 \mathrm{~h}$ for the temperature range 60 to $120^{\circ} \mathrm{C}$ are presented in Figure 2a. The intercalated compound $\alpha$-ZrP·2MIm was prepared by a reported method [14]. At $100{ }^{\circ} \mathrm{C}$, 
the $\%$ conversion value was $28 \%$ for $\alpha$-ZrP-2MIm-T, whereas a reaction did not occur for the addition of $\alpha$-ZrP.2MIm alone. At $120^{\circ} \mathrm{C}$, the $\%$ conversion value increased to $75 \%$, thus confirming the remarkable differences in reactivity as a result of TBD addition. To further examine the enhancement effects of TBD, the reactions were performed for $9 \mathrm{~h}$ at $100{ }^{\circ} \mathrm{C}$ (Figure $2 \mathrm{~b}$ ). For reactions of $2 \mathrm{~h}$ duration, the \%conversion values were $54 \%(\alpha-\mathrm{ZrP} \cdot 2 \mathrm{MIm}-\mathrm{T})$ and $6 \%(\alpha-\mathrm{ZrP} \cdot 2 \mathrm{MIm})$. When the reaction time was extended to $9 \mathrm{~h}$, the \%conversion value reached $89 \%$ for $\alpha-\mathrm{ZrP} \cdot 2 \mathrm{MIm}-\mathrm{T}$.
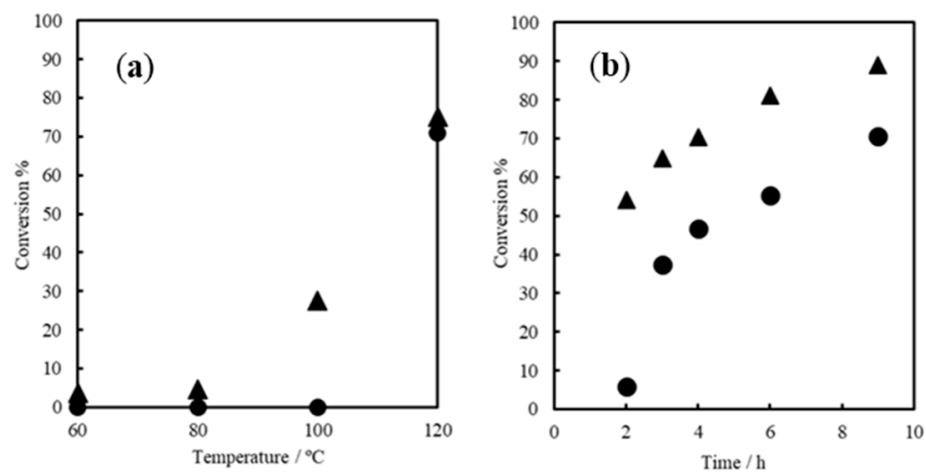

Figure 2. (a) The \%conversion values for GPE after $1 \mathrm{~h}$ as a function of temperature during reaction with $2 \mathrm{MIm}$ intercalated $\alpha$-zirconium phosphate $(\alpha$-ZrP·2Mim) $(\bullet)$ and $\alpha$-ZrP·2MIm with TBD $(\alpha-\mathrm{ZrP} \cdot 2 \mathrm{MIm}-\mathrm{T})(\boldsymbol{\Lambda}) ;(\mathbf{b})$ the \%conversion values for GPE as a function of time during reaction with $\alpha$-ZrP·2MIm $(\bullet)$ and $\alpha-Z r P \cdot 2 \mathrm{MIm}-\mathrm{T}$ at $100{ }^{\circ} \mathrm{C}(\mathbf{\Lambda})$.

To serve as a latent thermal initiator, the initiator in the epoxy monomer and prepolymer needs to have a high curing capability at the desired temperature and also display high stability under the recommended storage regime. To evaluate the long-term storage stability, the \%conversion values for GPE at 25 and $40{ }^{\circ} \mathrm{C}$ were studied for periods up to 14 days, and the results are presented in Figure 3 . With respect to storage stability and using a $20 \%$ conversion level as a typical benchmark, the \%conversion values were $19 \%$ at $25^{\circ} \mathrm{C}$ for 14 days and $16 \%$ at $40{ }^{\circ} \mathrm{C}$ for 4 days storage. The latent thermal initiating system of $\alpha$-ZrP-2MIm-T in GPE gave high reactivity at $100{ }^{\circ} \mathrm{C}$ and was shown to be stable for periods up to 14 days at a temperature of $25^{\circ} \mathrm{C}$.

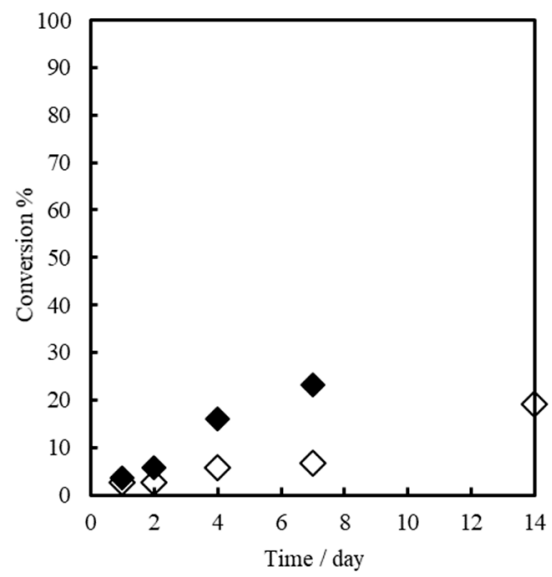

Figure 3. The \%conversion values for GPE as a function of time for reaction with $\alpha-\mathrm{ZrP} \cdot 2 \mathrm{MIm}-\mathrm{T}$ at $40{ }^{\circ} \mathrm{C}(\diamond)$ and $25^{\circ} \mathrm{C}(\diamond)$.

To study the reaction behavior of GPE with $\alpha-\mathrm{ZrP} \cdot 2 \mathrm{MIm}-\mathrm{T}$, the changes in composition after reaction of $\alpha$-ZrP.2MIm (abbreviated as $\alpha$-ZrP.2MIm-RXN) and $\alpha$-ZrP.2MIm-T (abbreviated as $\alpha-Z r P \cdot 2 M I m-T-R X N)$ were investigated. For this, an elemental analysis was performed after washing the reaction mixtures with THF to remove the reaction product of GPE. The elemental ratios for $\mathrm{C}, \mathrm{H}$, and $\mathrm{N}$ in $\alpha$-ZrP.2MIm-RXN were C: $13.93, \mathrm{H}: 1.86$, and $\mathrm{N}: 6.89$ at $100^{\circ} \mathrm{C}$ and $\mathrm{C}: 43.00, \mathrm{H}: 3.72$, and $\mathrm{N}: 0.97$ 
at $120^{\circ} \mathrm{C}$. In the case of $\alpha$-ZrP-2MIm-T-RXN, the respective ratios were C: $17.46, \mathrm{H}: 2.02$, and N: 6.19 at $100^{\circ} \mathrm{C}$ and $\mathrm{C}: 40.28, \mathrm{H}: 3.41$, and $\mathrm{N}: 1.76$ at $120^{\circ} \mathrm{C}$. The respective deintercalation ratios for $2 \mathrm{MIm}$ from the interlayer of $\alpha$-ZrP.2MIm were estimated as $4 \%$ and $74 \%$ and $9 \%$ and $57 \%$ from $\alpha$-ZrP.2MIm-T at $100{ }^{\circ} \mathrm{C}$ and $120^{\circ} \mathrm{C}$, respectively (Table 1). Estimations of the respective elemental compositions after reaction at $120^{\circ} \mathrm{C}$ for $\alpha$-ZrP·2MIm-RXN and $\alpha$-ZrP.2MIm-T-RXN were $\mathrm{Zr}\left(\mathrm{HPO}_{4}\right)_{2} \cdot 0.25 \mathrm{C}_{4} \mathrm{H}_{6} \mathrm{~N}_{2} \cdot 2.73 \mathrm{C}_{9} \mathrm{H}_{10} \mathrm{O}_{2}$ and $\mathrm{Zr}\left(\mathrm{HPO}_{4}\right)_{2} \cdot 0.41 \mathrm{C}_{4} \mathrm{H}_{6} \mathrm{~N}_{2} \cdot 2.27 \mathrm{C}_{9} \mathrm{H}_{10} \mathrm{O}_{2}$, thus signifying intercalation of the reaction product of GPE. The value for the deintercalation ratio for $\alpha$-ZrP.2MIm-T (57\%) was clearly lower than that for $\alpha$-ZrP·2MIm (74\%), suggesting enhanced reactivity for $\alpha$-ZrP·2MIm-T for GPE.

Table 1. Deintercalation ratios after $1 \mathrm{~h}$ of reaction with $\alpha$-ZrP.2MIm and $\alpha-\mathrm{ZrP} \cdot 2 \mathrm{MIm}-\mathrm{T}$ at $100{ }^{\circ} \mathrm{C}$ and $120^{\circ} \mathrm{C}$, and the respective elemental compositions.

\begin{tabular}{cccc}
\hline $\begin{array}{c}\text { After Reaction of } \\
\text { Initiator }\end{array}$ & Temperature/ ${ }^{\circ} \mathbf{C}$ & Deintercalation Ratio\% & Composition \\
\hline$\alpha$-ZrP·2MIm-RXN & 100 & 4 & $\mathrm{Zr}\left(\mathrm{HPO}_{4}\right)_{2} \cdot 0.91 \mathrm{C}_{4} \mathrm{H}_{6} \mathrm{~N}_{2} \cdot 0.07 \mathrm{C}_{9} \mathrm{H}_{10} \mathrm{O}_{2}$ \\
& 120 & 74 & $\mathrm{Zr}\left(\mathrm{HPO}_{4}\right)_{2} \cdot 0.25 \mathrm{C}_{4} \mathrm{H}_{6} \mathrm{~N}_{2} \cdot 2.73 \mathrm{C}_{9} \mathrm{H}_{10} \mathrm{O}_{2}$ \\
\hline$\alpha$-ZrP·2MIm-T-RXN & 100 & 9 & $\mathrm{Zr}\left(\mathrm{HPO}_{4}\right)_{2} \cdot 0.86 \mathrm{C}_{4} \mathrm{H}_{6} \mathrm{~N}_{2} \cdot 0.25 \mathrm{C}_{9} \mathrm{H}_{10} \mathrm{O}_{2}$ \\
& 120 & 57 & $\mathrm{Zr}\left(\mathrm{HPO}_{4}\right)_{2} \cdot 0.41 \mathrm{C}_{4} \mathrm{H}_{6} \mathrm{~N}_{2} \cdot 2.27 \mathrm{C}_{9} \mathrm{H}_{10} \mathrm{O}_{2}$ \\
\hline
\end{tabular}

To study the changes in the interlayer distances, the reactions for $\alpha$-ZrP·2MIm and $\alpha$-ZrP.2MIm-T were next investigated. The interlayer distance for $\alpha$-ZrP-2MIm did not change for a $1 \mathrm{~h}$ reaction performed at $100^{\circ} \mathrm{C}$. In the case of $\alpha$-ZrP·2MIm-T, a small XRD peak at $2 \theta=3.4^{\circ}$ (25.9 $\AA$ ) was observed, as shown in Figure $4 \mathrm{~b}$. This peak might reflect the intercalation of the products of GPE. At $120^{\circ} \mathrm{C}$, the interlayer distances were extended, and peaks were not detected from $3^{\circ}$ to $40^{\circ}$ for the two GPE products, as shown in Figure $4 \mathrm{c}, \mathrm{d}$. To detect peak shifts of less than $3^{\circ}$, the tube voltage was reduced from $40 \mathrm{kV}$ to $20 \mathrm{kV}$ and the XRD responses were recorded from $2^{\circ}$ to $15^{\circ}$ as shown in Figure $4 \mathrm{c}^{\prime}, \mathrm{d}^{\prime}$. The peaks associated with the interlayer distances were $2 \theta=2.8^{\circ}(31.2 \AA)$ for $\alpha$-ZrP.2MIm-RXN and $2 \theta=3.1^{\circ}(28.2 \AA)$ for $\alpha$-ZrP·2MIm-T-RXN, respectively.

(a)

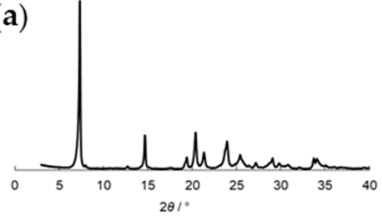

(b)

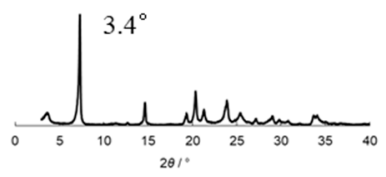

(c)

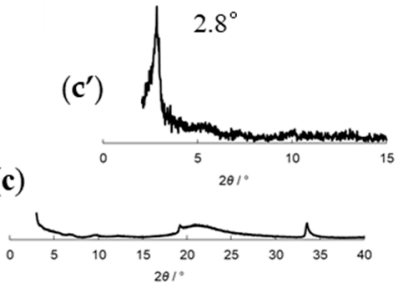

(d)

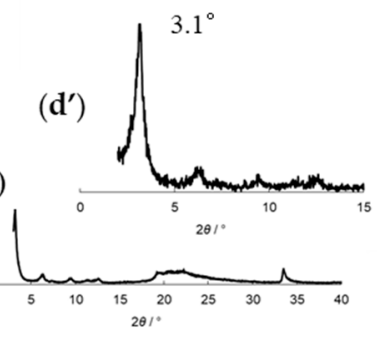

Figure 4. XRD patterns for (a) after reaction of $\alpha$-ZrP·2MIm $(\alpha-Z r P \cdot 2 \mathrm{MIm}-\mathrm{RXN})$ at $100{ }^{\circ} \mathrm{C}$, (b) after reaction of $\alpha$-ZrP.2MIm-T ( $\alpha$-ZrP.2MIm-T-RXN) at $100{ }^{\circ} \mathrm{C},\left(\right.$ c) $\alpha-Z r P \cdot 2 \mathrm{MIm}-\mathrm{RXN}$ at $120{ }^{\circ} \mathrm{C}$, (c') $\alpha$-ZrP.2MIm-RXN at $120{ }^{\circ} \mathrm{C}$ for $2 \theta=2^{\circ}-15^{\circ}$, (d) $\alpha$-ZrP.2MIm-T-RXN at $120{ }^{\circ} \mathrm{C}$, and $\left(\mathbf{d}^{\prime}\right)$ $\alpha-\mathrm{ZrP} \cdot 2 \mathrm{MIm}-\mathrm{T}-\mathrm{RXN}$ at $120^{\circ} \mathrm{C}$ for $2 \theta=2^{\circ}-15^{\circ}$.

To confirm the intercalation of the GPE products, FT-IR spectra were recorded and are presented in Figure 5. An absorption peak due to $\alpha-\mathrm{ZrP}(\nu \mathrm{P}-\mathrm{O})$ was detected at $1006 \mathrm{~cm}^{-1}$ as shown in Figure $4 \mathrm{a}$. Peaks associated with aromatic $\left(v \mathrm{C}-\mathrm{C}\right.$ at 1600,1497 and $\left.1458 \mathrm{~cm}^{-1}\right)$ and ether groups $(\vee \mathrm{C}-\mathrm{O}-\mathrm{C}$ at 
$1248 \mathrm{~cm}^{-1}$ ) in the respective products may be observed clearly in Figure $5 b, c$. No significant differences in the spectra in Figure $5 b, c$ were noted.
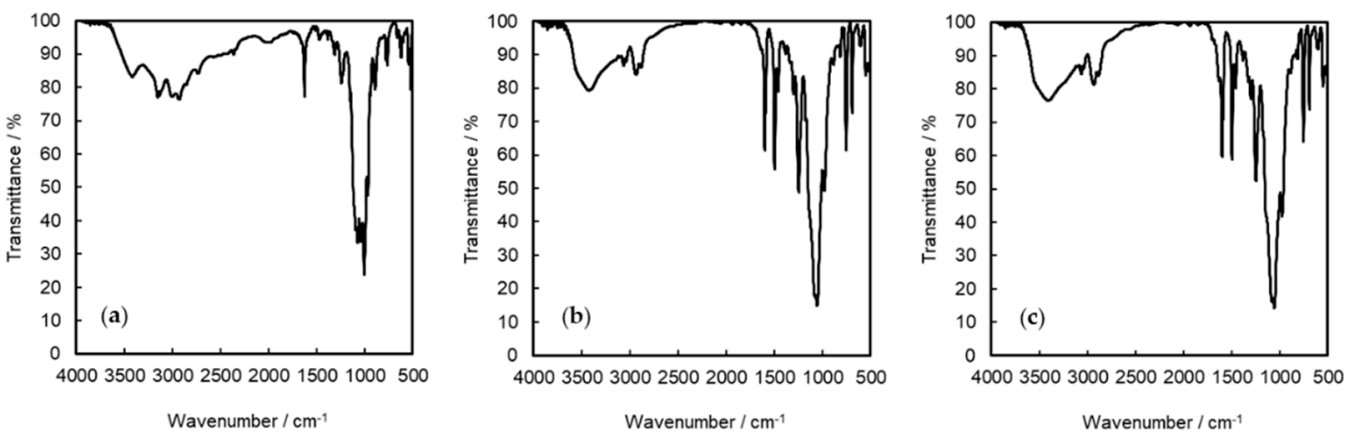

Figure 5. FT-IR spectra for (a) $\alpha$-ZrP-2MIm, (b) $\alpha$-ZrP·2MIm-RXN, and (c) $\alpha$-ZrP·2MIm-T-RXN.

Thus, the initiating system TBD with $\alpha$-ZrP.2MIm showed good storage stability at $25^{\circ} \mathrm{C}$ and high reactivity at $100{ }^{\circ} \mathrm{C}$, and offers great potential as a latent thermal initiator in the curing of epoxy resin.

\section{Experimental Section}

\subsection{Materials}

$\mathrm{Zr}\left(\mathrm{HPO}_{4}\right)_{2} \cdot \mathrm{H}_{2} \mathrm{O}(\mathrm{CZP}-100)$ was purchased from Daiichi Kigenso Kagaku Kogyo Co., Ltd. (Osaka, Japan). GPE was purchased from Aldrich Chemical Co., Inc. (Tokyo, Japan). TMG, TBD, MTBD, DBU, and DBN were purchased from Tokyo Chemical Industries, Co., Ltd. (Tokyo, Japan). The intercalated compound $\alpha-\mathrm{ZrP} \cdot 2 \mathrm{MIm}$ was prepared by a reported method [14]. The chemical composition of $\alpha$ - $\mathrm{ZrP} \cdot 2 \mathrm{MIm}$ was $\mathrm{Zr}\left(\mathrm{HPO}_{4}\right)_{2} \cdot 0.95 \mathrm{C}_{4} \mathrm{H}_{6} \mathrm{~N}_{2} \cdot 0.91 \mathrm{H}_{2} \mathrm{O}$. Solvents were used as received without further purification.

\subsection{Measurements}

X-ray diffraction (XRD) patterns were obtained using a RINT2200 (Rigaku, Tokyo, Japan) under the following operating conditions: $\mathrm{Cu} \mathrm{K} \alpha$ radiation of $40 \mathrm{kV}, 40 \mathrm{~mA}$ over a scan range of $3^{\circ}-40^{\circ}$ at a rate of $2^{\circ} \mathrm{min}^{-1}$ and for $20 \mathrm{kV}$, and $20 \mathrm{~mA}$ over a scan range of $2^{\circ}-15^{\circ}$ at a rate of $2^{\circ} \mathrm{min}^{-1}$. NMR spectra of solutions were recorded on a Unity-300 spectrometer (Varian, Palo Alto, CA, USA) and a JNM-ECZS (400 MHz) spectrometer (JEOL, Tokyo, Japan) using tetramethylsilane (TMS) as an internal standard. Elemental analyses were carried out using a 2400II analyzer (PerkinElmer, Waltham, MA, USA). Fourier transform infrared spectroscopy (FT-IR) measurements were carried out with an ALPHA spectrometer (Bruker, Billerica, MA, USA).

\subsection{Typical Polymerization Procedure}

A mixture of GPE (150 mg, $1.0 \mathrm{mmol})$, TBD $(4.2 \mathrm{mg}, 0.030 \mathrm{mmol})$, and an intercalated compound of 2-methylimidazole with $\alpha$-ZrP $(\alpha$-ZrP.2MIm) $(11.9 \mathrm{mg}, 0.032 \mathrm{mmol}$, and content of 2-methylimidazole: $0.030 \mathrm{mmol}$ ) was heated at $120^{\circ} \mathrm{C}$ for $1 \mathrm{~h}$. A small aliquot of the reaction mixture was dissolved in $\mathrm{CDCl}_{3}$, and its ${ }^{1} \mathrm{H}-\mathrm{NMR}$ spectrum was acquired to determine the extent of conversion of GPE.

\subsection{Polymerization Procedure for Recovery of $\alpha$-ZrP.2MIm ( $\alpha$-ZrP.2MIm-T-RXN) after the Reaction}

A mixture of GPE (4.51 g, $30.0 \mathrm{mmol})$, TBD (126 mg, $0.91 \mathrm{mmol})$, and $\alpha$-ZrP.2MIm (357 mg, $0.95 \mathrm{mmol}$, content of 2-methylimidazole: $0.90 \mathrm{mmol}$ ) was heated at $120{ }^{\circ} \mathrm{C}$ for $1 \mathrm{~h}$. After the reaction, tetrahydrofuran (THF) was added to the mixture. The solution was filtered and the residue $(\alpha-Z r P \cdot 2 M I m-T-R X N)$ was rinsed, dried under vacuum, and analyzed by XRD and FT-IR. 


\section{Conclusions}

A temperature-dependent enhancement effect was found for TBD with $\alpha$-ZrP.2MIm as a latent thermal initiator in the reaction of GPE. The reaction with GPE at $100{ }^{\circ} \mathrm{C}$ and for $1 \mathrm{~h}$ did not proceed, in contrast to that when TBD was added to $\alpha$-ZrP.2MIm $(\alpha-\mathrm{ZrP} \cdot 2 \mathrm{MIm}-\mathrm{T})$, and where a \%conversion value of $28 \%$ was attained. By extending the reaction time to $9 \mathrm{~h}$, the \%conversion value reached $89 \%$ for $\alpha$-ZrP.2MIm-T and 71\% for $\alpha$-ZrP.2MIm, respectively, confirming that the reactivity of GPE was increased by the addition of TBD. With respect to storage, $\alpha$-ZrP-2MIm-T in GPE was found to be stable for 14 days, with the \%conversion value being 19\%. The latent thermal initiator $\alpha$-ZrP-2MIm-T showed good stability under typical storage conditions $\left(7\right.$ days at $\left.25^{\circ} \mathrm{C}\right)$ and was highly reactive with GPE. Thus, the mixed initiator $\alpha$-ZrP.2MIm may be used as a latent thermal initiating system in the curing of epoxy resin.

Author Contributions: O.S. conceived, designed, and wrote the article; S.S. and K.K. performed the experiments; A.O. and R.N. contributed to helpful discussion.

Funding: This research was funded by Japan Science and Technology Agency, grant number VP29117939124.

Conflicts of Interest: The authors declare no conflict of interest.

\section{References}

1. Wang, Y.; Kimura, M.; Sudo, A.; Endo, T. Polymerization of epoxide with hydroxylamides as thermally latent initiators. J. Polym. Sci. A Polym. Chem. 2016, 54, 2611-2617. [CrossRef]

2. Guzman, D.; Ramis, X.; Fernandez-Francos, X.; Serra, A. New catalysts for diglycidyl ether of bisphenol A curing based on thiol-epoxy click reaction. Eur. Polym. J. 2014, 59, 377-386. [CrossRef]

3. Kirino, M.; Tomita, I. Aminimides derived from p-substituted benzoylformic acid ester as thermal/photolatent bases and photoradical initiators. J. Polym. Sci. A Polym. Chem. 2013, 51, 4292-4300. [CrossRef]

4. Sudo, A.; Yamashita, H.; Endo, T. Ring-opening polymerization of 1,3-benzoxazines by p-toluenesulfonates as thermally latent initiators. J. Polym. Sci. A Polym. Chem. 2011, 49, 3631-3636. [CrossRef]

5. Kirino, M.; Tomita, I. Aminimides Derived from Benzoylformic Acid Esters as Thermally Latent Base Catalysts. Macromolecules 2010, 43, 8821-8827. [CrossRef]

6. Xing, S.; Yang, J.; Huang, Y.; Zheng, Q.; Zeng, J. Preparation and characterization of a novel microcapsule-type latent curing agent for epoxy resin. Mater. Des. 2015, 85, 661-670. [CrossRef]

7. Shin, M.J.; Shin, Y.J.; Hwang, S.W.; Shin, J.S. Microencapsulation of imidazole curing agent by solvent evaporation method using W/O/W emulsion. J. Appl. Polym. Sci. 2013, 129, 1036-1044. [CrossRef]

8. Kudo, K.; Fuse, S.; Furutani, M.; Arimitsu, K. Imidazole-type thermal latent curing agents with high miscibility for one-component epoxy thermosetting resins. J. Polym. Sci. A Polym. Chem. 2016, 54, 2680-2688. [CrossRef]

9. Arimitsu, K.; Tomota, K.; Fuse, S.; Kudo, K.; Furutani, M. A non-linear organic reaction of malonate derivative as a base amplifier to generate imidazoles without producing gas. RSC Adv. 2016, 6, 38388-38390. [CrossRef]

10. Lei, D.; Ma, W.; Wang, L.; Zhang, D. Preparation of 2-ethyl-4-methylimidazole derivatives as latent curing agents and their application in curing epoxy resin. J. Appl. Polym. Sci. 2015, 132. [CrossRef]

11. Shimomura, O.; Maeno, K.; Ohtaka, A.; Yamaguchi, S.; Ichihara, J.; Sakamoto, K.; Nomura, R. Alkylamines-intercalated $\alpha$-zirconium phosphate as latent thermal anionic initiators. J. Polym. Sci. A Polym. Chem. 2014, 52, 1854-1861. [CrossRef]

12. Shimomura, O.; Ohtaka, A.; Nomura, R. Fatty amines-intercalated $\alpha$-zirconium phosphate as latent thermal curing agents. J. Adhes. Soc. Jpn. 2017, 53, 118-121. [CrossRef]

13. Shimomura, O.; Sasaki, S.; Kume, K.; Kawano, S.; Shizuma, M.; Ohtaka, A.; Nomura, R. Release behavior of benzimidazole-intercalated $\alpha$-zirconium phosphate as a latent thermal initiator in the reaction of epoxy resin. Catalysts 2019, 9, 69. [CrossRef]

14. Shimomura, O.; Tokizane, K.; Nishisako, T.; Yamaguchi, S.; Ichihara, J.; Kirino, M.; Ohtaka, A.; Nomura, R. Imidazoles-intercalated $\alpha$-zirconium phosphate as latent thermal initiators in the reaction of glycidyl phenyl ether (GPE) and hexahydro-4-methylphthalic anhydride (MHHPA). Catalysts 2017, 7, 172. [CrossRef] 
15. Shimomura, O.; Nishisako, T.; Yamaguchi, S.; Ichihara, J.; Kirino, M.; Ohtaka, A.; Nomura, R. DABCO- and DBU-intercalated $\alpha$-zirconium phosphate as latent thermal catalysts in the copolymerization of glycidyl phenyl ether (GPE) and hexahydro-4-methylphthalic anhydride (MHHPA). J. Mol. Catal. A Chem. 2016, 411, 230-238. [CrossRef]

16. Shimomura, O.; Suetou, R.; Kusu, H.; Ohtaka, A.; Nomura, R. Effect of particle size of DABCO- and DBUintercalated $\alpha$-zirconium phosphate as latent thermal catalysts in the reaction of glycidyl phenyl ether (GPE) and hexahydro-4-methylphthalic anhydride (MHHPA). J. Adhes. Soc. Jpn. 2018, 54, 258-263. [CrossRef]

(C) 2019 by the authors. Licensee MDPI, Basel, Switzerland. This article is an open access article distributed under the terms and conditions of the Creative Commons Attribution (CC BY) license (http://creativecommons.org/licenses/by/4.0/). 